\title{
O processo de fechamento das escolas rurais nos municípios de Arraias e Combinado - TO
}

The process of shutdown rural schools in the cities of Arraias and Combinado TO

Edivaldo Barbosa de Almeida Filho Deyvison Bispo de Oliveira Santos Sátila Menezes Aires Floriza Beatriz de Sena Paula

\begin{abstract}
Resumo As políticas de Educação do Campo têm se consolidado nos movimentos sociais por um projeto político e pedagógico de emancipação dos povos do campo. $\mathrm{O}$ recorte desta pesquisa delimita-se entre o período de 1998 a 2015, cujo objetivo é investigar os marcos normativos da educação do campo que asseguram o direito à educação pública de qualidade aos povos camponeses e compreender as políticas de fechamento das escolas rurais localizadas em Arraias e Combinado no estado do Tocantins. Em termos metodológicos, utilizamos como fonte de pesquisa a revisão bibliográfica e documental na organização e sistematização de fontes primárias. A partir disso a pesquisa revela que o fechamento das escolas rurais nos devidos municípios evidencia a negação do direito à educação no ambiente em que vivem. Sendo assim, os direitos educacionais conquistados foram violados pelo poder público no processo de mobilização e organização das comunidades rurais.
\end{abstract}

Palavras-chave: Políticas Públicas, Escolas do Campo, Fechamento das Escolas Rurais.

Abstract The Rural Education policies have been consolidated in social movements by a political and pedagogical project for the rural folks emancipation. That research's center of attention is bounded between the period from 1998 to 2015, and having as target to inquire the Rural Education normative marks that it ensures the right to a bestquality public education for peasant folks and understanding the shutdown policies of rural schools localized in Arraias and Combinado in the Tocantins State. When it comes to the methodological outlook, we've adopted the bibliographic and documentary review as a research source in the organization and systematization of primary sources. From now there, the research reveals that the rural schools shutdown in the proper cities shows the denial of the right to education in the environment in where they live. Thus, the educational rights conquered were infringed by the public authorities in the process of rural communities mobilization and organization.

Keywords: Public Policies, Rural Schools, Rural Schools Shutdown.

\section{Introdução}

Em meados da década de 1990 o Movimento dos Trabalhadores Rurais Sem Terra (MST) juntamente com a Comissão Pastoral da Terra (CPT), Conferência Nacional dos Bispos do Brasil (CNBB) entre outras se reuniram em Brasília a fim de consolidar o "I Encontro Nacional de Educadoras e Educadores da Reforma Agrária" (I ENERA), realizado em julho de 1997, na Universidade 
de Brasília (MUNARIM, 2008). Apresentando o manifesto por uma proposta de educação contextualizada, emancipatória e transformadora, pautada no protagonismo da classe trabalhadora.

Ao longo de duas décadas de existência, o Movimento Nacional Por Uma Educação do Campo conquistou espaços na agenda política e marcos legais importantes na legislação educacional brasileira. $\mathrm{Na}$ atualidade vivenciamos contradições ao direito à educação da classe trabalhadora, que se manifesta contra o fechamento das escolas do campo e na luta em defesa da educação pública e de qualidade. Embora esta conquista tenha sido um grande avanço na consolidação da Educação do Campo, o poder público ainda é uma constante ameaça para a efetividade do conhecimento crítico enquanto direito universal.

O movimento por uma Educação do Campo tem afirmado outra proposta pedagógica, como o reconhecimento de suas identidades enquanto política pública. No entanto, nos últimos anos somos provocados a compreender 0 fechamento exorbitante das escolas localizadas no campo em todo o território nacional. Por que este fenômeno se intensificou na última década? É neste contexto que surge o problema de pesquisa, com o objetivo de compreender o fechamento das escolas localizadas na zona rural, dos municípios de Arraias e Combinado-Tocantins.

Em termos metodológicos realizamos a pesquisa bibliográfica com a finalidade de identificar as principais contribuições teóricas existentes sobre a Educação do Campo e a caracterização sócio histórica dos municípios de Arraias e Combinado.

Articulada à pesquisa bibliográfica optou-se pela pesquisa documental por fornecer ao investigador a possibilidade de reunir uma grande quantidade de informações em fontes distintas (TRIVIÑOS, 2010). A pesquisa documental realizada nas Secretarias Municipais de Educação, a partir da análise dos livros de matrículas, cadernos de resultados finais, relatórios dos censos escolares e dos bancos de dados do INEP, os quais foram fundamentais para a revisão de literatura e para o mapeamento do fechamento das escolas rurais dos municípios de Arraias e Combinado-Tocantins. Essa etapa da pesquisa possibilitou identificar e conhecer nos documentos oficiais, as escolas rurais desativadas, 
quantitativo de estudante por ano nas escolas rurais, quantidade de estudantes transportado da zona rural para as escolas da zona urbana.

No processo de organização, sistematização e interpretação dos dados a pesquisa focou em apresentar e discutir as escolas rurais desativadas. Utilizamos o método análise de conteúdo, direcionado pelos pressupostos de "que constitui no procedimento de pesquisa que se situa em um delineamento mais amplo da teoria da comunicação e tem como ponto de partida a mensagem" (Franco 2012, p. 25).

A verificação do conteúdo contribuiu para organização, direcionamento e sistematização dos dados da pesquisa para chegar à amostragem de tabelas. Durante a investigação, concluímos que atualmente o número de estudantes transportados do campo para escolas polo e urbanas é significativo. Evidenciamos que com a promulgação das Diretrizes Operacionais para a Educação Básica nas Escolas do Campo, a população é legitimada ao direito de abertura de parte das escolas desativadas.

\section{Marcos normativos da educação do campo}

A educação do campo percorre por transformações no modo de organização dos camponeses seja em conflitos agrários ou por educação do campo. A luta pela terra e posteriormente pela escola e remota dos movimentos dos trabalhadores rurais sem terra por um direito negado a todos os povos residentes do campo.

Em um passado histórico a educação rural não exercia função agregadora aos trabalhadores rurais por vários fatores, sendo um deles a própria pedagogia ofertada em uma educação rural que não exercia uma função emancipatória aos campesinos. O objetivo do ensino era de interesse do mercado externo na formação e qualificação da mão de obra campesina. No início da década de 1980 as mães e professoras, juntamente com lideranças sindicais começaram a se mobilizar por um projeto de educação no campo e tal articulação conquistou os marcos normativos para as escolas do campo (CALDART, 2003).

Esses enfrentamentos sobrevivem nos dias atuais com o fechamento das escolas no campo em todo o país, funcionando como uma agressão à cidadania 
dos filhos e filhas dos trabalhadores rurais. Assim, podemos atribuir que o encerramento das escolas nas comunidades tradicionais ocorre pela imposição feita pelo poder público nas unidades educacionais dos municípios de Arraias e Combinado no estado do Tocantins, em manter escolas tradicionais em sua organização de ensino, aniquilando o ingresso e a permanência dos educandos nas escolas.

Desse modo, a partir da historicização da educação rural no Brasil, a nomenclatura passou por amplas discussões no termo, carregado de contextos conotativos sobre os sujeitos que vivem em diversos territórios de nosso país. Para KOLLING; NERY; MOLINA, 1999, p. 26 apud CALDART 2012, p. 260).

Utilizar-se-á a expressão campo, e não a mais usual, meio rural, com o objetivo de incluir no processo da conferência uma reflexão sobre o sentido atual do trabalho camponês e das lutas sociais e culturais dos grupos que hoje tentam garantir a sobrevivência desse trabalho. Mas, quando se discutir a educação do campo, se estará tratando da educação que se volta ao conjunto dos trabalhadores e das trabalhadoras do campo, sejam os camponeses, incluindo os quilombolas, sejam as nações indígenas, sejam os diversos tipos de assalariados vinculados à vida e ao trabalho no meio rural. Embora com essa preocupação mais ampla, há uma preocupação especial com o resgate do conceito de camponês. Um conceito histórico e político $(\ldots)$

Sendo assim, retomemos a importância da luta dos movimentos sociais para a inclusão da pedagogia do movimento entre as prioridades/demandas necessárias a serem pautadas no debate político. A partir disso, a Lei de Diretrizes e Bases da Educação Nacional - LDB nº 9.394 de 1996, faz referência em sua estrutura que:

Art. $\mathbf{2 6}^{\circ}$. Os currículos do ensino fundamental e médio devem ter uma base nacional comum, a ser complementada, em cada sistema de ensino e estabelecimento escolar, por uma parte diversificada, exigida pelas características regionais e locais da sociedade, da cultura, da economia e da clientela.

Art. $\mathbf{2 8}^{\circ}$. Na oferta de educação básica para a população rural, os sistemas de ensino promoverão as adaptações necessárias à sua adequação às peculiaridades da vida rural e de cada região, especialmente:

I - Conteúdos curriculares e metodologias apropriadas às reais necessidades e interesses dos alunos da zona rural; 
II - Organização escolar própria, incluindo adequação do calendário escolar às fases do ciclo agrícola e às condições climáticas;

III - adequação à natureza do trabalho na zona rural (BRASIL, 1996).

Entre as reivindicações do Movimento da Educação do Campo, destacase que em março de 2014 foi acrescentado um parágrafo único no artigo 28 da LDB pela Lei 12.960/2014 por instituir que a complementação no Artigo 28 sinaliza que para fechar uma escola no campo é preciso que antes seja dialogado com a comunidade local e que seja elaborado um diagnóstico do impacto da ação e a manifestação da comunidade escolar. Esta complementação na lei seria uma grande conquista, porém muitas escolas estão fechadas devido o poder público municipal deixar implícito às comunidades que a escola urbana seja a melhor se comparada com a escola rural.

No entanto, a argumentação é a de que o poder público não tem condições de manter as escolas rurais devido à falta de financiamento a nível estadual e nacional, e que as escolas rurais têm alto custo se levado em consideração o menor contingente de estudantes da escola do campo com a escola dos centros urbanos. Ainda sobre a educação do campo, tal modalidade de ensino atendia o viés pedagógico das escolas urbanas, colocando de lado todas as peculiaridades da vida rural e de cada região.

Anterior a Lei 12.960/2014, a efetivação das Diretrizes Operacionais para a Educação Básica nas Escolas do Campo, Resolução CNE/CEB 1, de 3 de abril de 2002, no Artigo $2^{\circ}$, ainda hoje é um grande desafio, pois muitas escolas localizadas no campo desconhecem a educação do campo e os marcos legais conquistados nas duas últimas décadas no âmbito do ensino brasileiro:

Estas Diretrizes, com base na legislação educacional, constituem um conjunto de princípios e de procedimentos que visam adequar o projeto institucional das escolas do campo às Diretrizes Curriculares Nacionais para a Educação Infantil, para o Ensino Fundamental, para o Ensino Médio, para a Educação de Jovens e Adultos, para a Educação Especial, para a Educação Indígena, para a Educação Profissional de Nível Técnico e para a Formação de Docentes da Educação Infantil e dos anos iniciais do Ensino Fundamental, em Nível Médio, na modalidade Normal. (BRASIL, 2002, p. 282). 
Nessa dinâmica, as diretrizes constituem um grande avanço para a população do campo, com a garantia do acesso à educação em todas as modalidades de ensino. Em 2008 é publicado às Diretrizes Complementares Resolução $n^{\circ} 2$ de 28 de abril de 2008, que aponta as normas e princípios para o desenvolvimento de políticas públicas de atendimento da Educação Básica do Campo.

A Portaria n 391 de 10 de maio de 2016 é estabelecida no âmbito do Ministério da Educação orientando as Secretarias de Educação e os Conselhos Estaduais e Municipais de Educação como proceder administrativamente que tratam do fechamento das escolas do campo. Estas orientações visam à garantia do direito às comunidades rurais terem escolas do campo e garantindo a participação das populações rurais nesse processo.

Para tanto, percebe-se que as conquistas acerca das políticas públicas educacionais foram significativas nesse período, todavia, é necessário exigir do poder público o cumprimento da lei, visando garantir, a continuidade das políticas públicas. Assim, os sujeitos que vivem no campo poderão, de fato, participar dos processos formativos como cidadãos de direito.

Os marcos legais conquistados até hoje são fundamentais para a manutenção do território enquanto espaço de vida- "o campo, é mais do que um perímetro não urbano, é um campo de possibilidades que dinamizam a ligação dos seres humanos com a própria produção das condições da existência social e com as realizações da sociedade humana" (PARECER № 36, 2001, p. 1).

Todas as conquistas do Movimento Nacional da Educação do Campo expressam a preocupação com o direito ao ensino de qualidade para os povos do campo, a fim de garantir o acesso e permanência ao ambiente escolar. Sendo assim, tais conquistas buscam instituir os papéis dos municípios e estados a delegar limites e horizontalidade às decisões.

É, portanto, fundamental a relação entre Estado e sociedade no sentido de assegurar as condições necessárias para a existência e funcionamento das escolas do campo, bem como garantir o diálogo e protagonismo dos camponeses no processo educativo e de efetivação das políticas públicas. 


\section{Diálogos em defesa da escola do campo}

É preciso compreender e entender os conflitos e as contradições que emergem no contexto educacional, para que possamos nos posicionar frente à luta pelo direito à educação dos camponeses e pelo direito a escola pública de qualidade e democrática. Para Ravitch (2010) apud Freitas (2012), em defesa da escola pública argumenta:

As escolas são um patrimônio nacional público que, se for apropriado pela iniciativa privada, põe em risco a própria noção de democracia. Somente um espaço público pode lidar com a formação da juventude de forma a atender aos interesses nacionais dentro da necessária pluralidade de opiniões existentes no âmbito da sociedade. Os objetivos da educação são amplos e devem, sobretudo, permitir o desenvolvimento multilateral de nossa juventude. (RAVITCH; 2010 apud FREITAS, 2012, p. 396).

É necessário, uma escola pública de qualidade e democrática que garanta aos estudantes o acesso aos diversos conhecimentos, e que também possa expandir todas as suas habilidades. Portanto, cabe a defesa de uma escola unitária, que supere o dualismo da organização social brasileira, com consequências para a organização do sistema educacional. (FRIGOTTO; CIAVATTA, 2003, p. 120). A escola deve ser promotora da formação de cidadãos críticos e participativos.

A I Conferência Nacional Por Uma Educação Básica no Campo realizada em julho de 1998, em Luziânia-Goiás, mostrou novas iniciativas para contribuir com a Educação do Campo. Temos a destacar, segundo Caldart (2009), que outras reflexões podem ser discutidas.

1) A Educação Básica do Campo está sendo produzida neste movimento, nesta dinâmica social, que é também sociocultural de humanização das pessoas que dele participam.

2) Existe uma nova prática de Escola que está sendo gestada neste movimento. Nossa sensibilidade de educadores já nos permite perceber que existe algo diferente e que pode ser uma alternativa em nosso horizonte de trabalhador da educação, de ser humano. Precisamos aprender a potencializar os elementos presentes nas diversas experiências, e transformá-lo 
em movimento consciente de construção de escolas do campo como escolas que ajudem neste processo mais amplo de humanização, e de reafirmação dos povos do campo como sujeitos de seu próprio destino, de sua própria história. (CALDART, 2009, p. 89-90, grifos do autor)

Segundo Caldart (2009) essas ideias são a base para entendermos que tipo de escola está sendo produzida pelo movimento social do campo em nosso país. O papel da escola nessa luta por um novo projeto de desenvolvimento social, na construção de uma pedagogia do movimento baseada na luta dos trabalhadores rurais. Em suma, um processo pedagógico transformador que atenda aos objetivos da realidade social como um todo. $E$ que as questões inerentes à realidade das organizações sociais devam ser problematizadas no debate público.

Os movimentos de reforma agrária integram nas lutas sociais por terra e educação (MOLINA; SÁ, 2012). A escola do campo está articulada ao projeto de educação da classe trabalhadora, propondo construir uma prática educativa que fortaleça a luta dos camponeses. Logo o artigo $4^{\circ}$ das Diretrizes Operacionais para a Educação Básica nas Escolas do Campo, insere que:

O projeto institucional das escolas do campo, expressão do trabalho compartilhado de todos os setores comprometidos com a universalização da educação escolar com qualidade social, constituir-se-á num espaço público de investigação e articulação de experiências e estudos direcionados para o mundo do trabalho, bem como para o desenvolvimento social, economicamente justo e ecologicamente sustentável (BRASIL, 2002, p. 282).

Assim, fica nítido que o projeto das escolas do campo exposto pelas Diretrizes Operacionais para a Educação Básica nas Escolas do Campo contribui para o desenvolvimento social e sustentável em articulação ao saber dos povos do campo como estratégias pedagógicas categórico ao movimento.

Falar em escolas do campo é também reconhecer as lutas do Movimento dos Trabalhadores Rurais Sem Terra (MST), que trouxeram no bojo da luta pela reforma agrária a reivindicação por escola do campo, sobretudo, para cultivar em si mesmo o valor do estudo e do próprio direito de lutar pelo seu acesso a ele. (CALDART, 2009). 
A luta do MST pelo direito à educação está articulada a um conjunto de sujeitos coletivos, a saber: os atingidos por barragem e mineração, a luta dos povos indígenas, a luta dos quilombolas pelo reconhecimento de seus territórios, a luta das mulheres camponesas, a luta pela reforma agrária entre outras tantas lutas presentes no território dos camponeses. Neste cenário, a conquista da terra é o início da luta, pois esta se fortalece, uma vez que a classe trabalhadora tenha o direito à terra, ao trabalho, à cultura e à educação. Fernandes, Cerioli e Caldart (2009) argumentam:

No contexto atual do nosso país, defender políticas públicas específicas para o campo não significa discriminá-lo ou pretender insistir numa postura dicotômica entre rural e urbano. Ao contrário, no nosso caso, precisamos de políticas específicas para romper com o processo de discriminação, para fortalecer a identidade cultural negada aos diversos grupos que vivem no campo, e para garantir atendimento diferenciado ao que é diferente, mais que não deve ser desigual. (FERNANDES; CERIOLI; CALDART, 2009, p. 49).

As políticas públicas voltadas para a Pedagogia do Movimento visam a superação da concepção de educação rural e à garantia da democratização da educação pública, ao saber que valoriza o campo e os sujeitos coletivos na construção de um projeto educacional. Acredita-se em uma escola em que as potencialidades educadoras no desenvolvimento das mudanças de relações de poder, reconheçam a luta pela terra no fazer pedagógico de acordo com a realidade das crianças, jovens e adultos no campo e na cidade. Neste sentido, é fundamental conhecer e fomentar reflexões sobre nossa história para iniciar um trabalho de transformação social.

Não existe um modelo de escola ideal, mas um movimento constante de publicizar a história da luta dos movimentos em prol de uma educação inclusiva, igualitária e de qualidade, que esteve sempre dialogando em defesa da Educação do Campo e que impulsiona o homem e a mulher a terem a consciência de si, como sujeitos transformadores de sua própria existência.

A Escola do Campo está em constante movimento. "Uma escola em movimento é aquela que vai fazendo e refazendo as ações educativas do seu dia a dia, levando em conta os modos de produção de vida e participando ativamente do processo de formação" (CALDART, 2003, p. 76). 


\section{A problemática do fechamento das escolas localizadas no campo}

O Artigo $2^{\circ}$ das Diretrizes Operacionais para a Educação Básica nas Escolas do Campo traz contribuições para as identidades dos sujeitos campesinos e também aborda o respeito à identidade das escolas situadas mais próximas aos camponeses como uma prática social de emancipação:

Parágrafo único. A identidade da escola do campo é definida pela sua vinculação às questões inerentes à sua realidade, ancorando-se na temporalidade e saberes próprios dos estudantes, na memória coletiva que sinaliza futuros, na rede de ciência e tecnologia disponível na sociedade e nos movimentos sociais em defesa de projetos que associem as soluções exigidas por essas questões à qualidade social da vida coletiva no país. (BRASIL, 2002, p. 282).

A finalidade é a execução de uma política de Educação que, além de perceber, deverá respeitar a diversidade cultural e as diversas experiências de educação em desenvolvimento em todas as localidades do Brasil. Só assim, portanto, será possível propor o aumento de oferta da educação básica e de jovens e adultos nas escolas do campo.

\section{Desencadeamento das escolas rurais entre 1997 e 2015}

No Brasil, a chamada Educação Rural foi arquitetada como um espaço de atraso científico, intelectual e cultural. Esse distanciamento de princípios através do discurso legitimado pelo interesse do capital, instala no campo como objeto de progresso, político e latifundiário. São discursos que vislumbram os camponeses como indignos de seus territórios. Nesse processo, a educação dos indivíduos que vivem no campo foi tomada como espaços de relações horizontais sem importância (TAFFAREL; JÚNIOR; ESCOBAR, 2010, p. 50).

Estes problemas evidenciam o estigma de que as escolas urbanas sejam melhores se comparadas às escolas rurais, silenciando a cultura e identidade dos povos do campo. De acordo com os dados do Instituto Nacional de Estudos e Pesquisas Educacionais Anísio Teixeira (INEP), referente ao censo escolar de 2014, somente no mesmo ano, 4.084 escolas rurais foram fechadas em todo o 
Brasil. Este número alarmante de escolas fechadas preocupa entidades e movimentos sociais ligados ao campo e à educação, devido os municípios pequenos e mais pobres serem os mais afetados (MST, 2015).

O desencadeamento do fechamento das escolas rurais está articulado à nucleação das escolas, ou seja, a reunião de várias escolas em uma única unidade escolar. Nessa dinâmica, evidencia-se duas situações: a primeira constitui na transferência das crianças e jovens do campo para escolas polos, em muitas situações tais unidades são distantes da residência dos estudantes e nem sempre o transporte escolar garante o acesso todos os educandos a escola.

Em Arraias no Estado do Tocantins esse processo educacional é evidentemente expresso com o fechamento de unidades escolares rurais, principalmente no que diz respeito à oferta das séries iniciais e finais do ensino fundamental.

Tabela 1: Número de Escolas fechadas no campo em Arraias -TO entre 2000-2015.

\begin{tabular}{|c|c|}
\hline Município & Número de escolas fechadas \\
\hline Arraias & 23 \\
\hline
\end{tabular}

Fonte: Secretaria Municipal de Educação de Arraias -TO/2015.

A segunda situação corresponde à transferência das crianças e jovens das escolas do campo para escolas urbanas, ao título de exemplo no Município de Combinado-Tocantins no qual as crianças e jovens são submetidas à política do transporte escolar, e assim seguem enfrentando problemas diversos - "os estudantes hoje permanecem mais tempo dentro do transporte escolar do que propriamente dentro da sala de aula", muitos estudantes desistem da escola por causas das condições precárias de acesso entre outras.

Tabela 1: Número de Escolas fechadas no campo em Combinado -TO entre 1997-2015.

\begin{tabular}{|c|c|}
\hline Município & Número de escolas fechadas \\
\hline Combinado & 07 \\
\hline
\end{tabular}

Fonte: Secretaria Municipal de Educação - Combinado -TO/2015. 
Essa problemática perpassa em todo território nacional. Nos municípios de Arraias e Combinado, os estudantes do campo conduzidos para as escolas polos e urbanas permanecem muitas horas no transporte escolar em função da distância e das rotas estabelecidas pelas prefeituras.

Os dados revelam que as escolas foram fechadas a partir de argumentos dos gestores em que a nucleação visa atender melhor às necessidades dos estudantes e dos municípios. Contudo esse processo de fechamento das unidades escolares não teve o consentimento dos pais e das comunidades rurais (quilombolas, ribeirinhos, camponeses, agricultores familiares, etc.) sendo, portanto, uma decisão exclusivamente do poder municipal. Assim, o parágrafo único do artigo 28 da LDB de março de 2014, fica garantido o não fechamento das escolas do campo sem que antes seja dialogado com toda a comunidade local.

Nesse sentido, "é a escola que deve ajustar-se, em sua forma é conteúdo, aos sujeitos que dela necessitam; é a escola que deve ir ao encontro dos educandos, e não o contrário" (CALDART, 2003, p.63), a nucleação promovido pelo fechamento das unidades escolares são atitudes autoritárias contra os povos do campo. Demonstra uma negação ao direito de acesso à educação no espaço em que vivem, sendo importante que as populações do campo compreendam o direito à educação pública de qualidade para que as ações coletivas não sejam descaracterizadas.

\section{Considerações finais}

A Educação do Campo traz uma nova concepção de educação, do campo e da escola do campo articulada ao projeto de desenvolvimento de campo e de sociedade. A Educação do Campo compreende o campo como espaço de vida, cultura, trabalho e de sujeitos de história e de direitos (ARROYO, 2009).

A "Educação do Campo não cabe em uma escola" (CALDART, 2009, p. 156), ela pode ir além, está na vivência dos povos do campo, na cultura, na luta pela terra e na defesa pela escola pública e de qualidade. A escola tem um 
importante papel educativo, sendo esta voltada para a formação das novas gerações, buscando repassar conhecimentos adquiridos pela comunidade para lidar com os saberes tradicionais.

Neste trabalho procuramos evidenciar o fechamento das escolas do campo nos municípios de Arraias e Combinado -TO. Neste contexto, as investigações revelam que a escola do campo expressa muito mais que escola - é espaço de mobilização e organização da comunidade, de cultura, de valorização da identidade camponesa. Nas escolas desativadas aconteciam as campanhas de vacinação, as reuniões de organização dos agricultores, as celebrações religiosas, as reuniões de pais e as festas das localidades e comunidades vizinhas. Com o processo de fechamento das escolas, as coletividades perderam boa parte do potencial de articulação e realização das diversas manifestações sociais.

Conclui-se que o maior desafio da Educação do Campo consiste na luta contra o fechamento das escolas e na luta pelo direito à educação dos camponeses, o que implica no movimento intenso de luta pela reabertura das escolas do campo que foram fechadas, e na ampliação das modalidades de ensino. Permitindo o acesso e permanência de todos os que residem no campo ao percurso educativo com qualidade e à conclusão exitosa da escolarização até o seu mais elevado patamar (TAFFAREL; MUNARIM, 2015).

Sugerimos que os camponeses e a sociedade civil reivindiquem a permanência das escolas no campo, pois é crime fechar escolas rurais sem o diálogo com as comunidades. Sendo assim, o "campo" deve estar em constante movimento - agricultores familiares resistindo às imposições do poder público.

\section{Referências}

ARROYO, Miguel Gonzalez. A Educação Básica e o Movimento Social do Campo. In: ARROYO, Miguel Gonzalez; CALDART, Roseli Salete; MOLINA, Mônica Castagna (org.). Por uma educação do campo. 4. ed. Petrópolis, RJ: Vozes, 2009.

BRASIL. Constituição da República Federativa do Brasil: texto constitucional promulgado em 5 de outubro de 1988. 35. ed. Brasília: Câmara dos Deputados, Edições Câmara, 2012. Disponível em: <http://bd.camara.gov.br>. Acesso em: 25 nov. 2015. 
. Lei $n^{\circ}$ 9.394, de 20 de dezembro de 1996. Brasília. Disponível em: <http://www. planalto.gov.br/ccivil 03/leis/L9394.htm>. Acesso em: 25 nov. 2015.

. Lei $\mathrm{n}^{\circ}$ 12.960, de 27 de Março de 2014. Disponível em: <http://www.planalto.gov.br/ccivil 03/ Ato2011-2014/2014/Lei/L12960.htm>. Acesso em: 11 jan. 2016.

. Ministério da Educação. Resolução CNE/CEB no 1, de 03 de abril de 2002. In: BRASIL. Ministério da Educação/Secretaria de Educação Continuada, Alfabetização e Diversidade e Inclusão. Diretrizes Curriculares Nacionais da Educação Básica. Brasília: MEC, SEB, DICEI, 2013. p. 282-284.

. Ministério da Educação. Parecer CNE/CEB n 36, de 04 de dezembro de 2001. In: BRASIL. Ministério da Educação/Secretaria de Educação Continuada, Alfabetização e Diversidade e Inclusão. Diretrizes Curriculares Nacionais da Educação Básica. Brasília: MEC, SEB, DICEI, 2013. p. 267-281.

. Ministério da Educação. Resolução $n^{\circ}$ 2, de 28 de abril de 2008. In: BRASIL. Ministério da Educação/Secretaria de Educação Continuada, Alfabetização e Diversidade e Inclusão. Diretrizes Curriculares Nacionais da Educação Básica. Brasília: MEC, SEB, DICEI, 2013. p. 295-297.

Disponível

Ministério da Educação. Portaria $n^{\circ}$ 391, de 10 de maio de 2016.

<pronacampo.mec.gov.br/images/pdf/portaria_391_10052016.pdf>. Acesso em: 10 de out. 2017.

CALDART, Roseli Salete. A Escola do Campo em Movimento: Currículo sem Fronteiras. v. 3, n.1, pp.60-81, Jan/Jun 2003. Disponível em: $<$ www.ia.ufrri.br/ppgea/conteudo/conteudo-2009-1/Educacao-

MII/3SF/A ESCOLA DO CAMPO EM MOVIMENTO.pdf>. Acesso em: 12 jan. 2016.

, Roseli Salete. A Escola do Campo em Movimento. In: ARROYO, Miguel Gonzalez; CALDART, Roseli Salete; MOLINA, Mônica Castagna (org.). Por uma educação do campo. 4. ed. Petrópolis, RJ: Vozes, 2009. p. 87-131.

, Roseli Salete. Educação do Campo. In: CALDART, Roseli Salete; PEREIRA, Isabel Brasil, ALENTEJANO, Paulo; FRIGOTTO, Gaudêncio. Dicionário da Educação do Campo. Rio de Janeiro, São Paulo: Escola Politécnica de Saúde Joaquim Venâncio, Expressão Popular, 2012. p. 259-266.

FERNANDES, Bernardo Mançano; CERIOLI, Paulo Ricardo; CALDART, Roseli Salete. Primeira Conferência Nacional "Por uma Educação Básica do Campo". In: ARROYO, Miguel Gonzalez; CALDART, Roseli Salete; MOLINA, Mônica Castagna (org.). Por uma educação do campo. 4. ed. Petrópolis, RJ: Vozes, 2009. p. 19-63. 
FRANCO, Maria Laura Publisi Barbosa. Análise de Conteúdo. Brasília, 4. ed: Liber Livro, 2012.

FREITAS, Luiz Carlos de. Os Reformadores Empresarias da Educação: da Desmoralização do Magistério a Destruição do Sistema Público de Educação. Educ. Soc., Campinas, v. 33, n. 119, p. 379-404, abr.-jun. 2012. Disponível em: <http://www.cedes.unicamp.br>. Acesso em: 20 mar. 2016.

FRIGOTTO, Gaudêncio. CIAVATTA, Maria. Educação Básica no Brasil na década de 1990: subordinação ativa e consentida à lógica do mercado. Educ. Soc., Campinas, vol. 24, n. 82, p. 93-130, abril, 2003. Disponível em: <http://www.cedes.unicamp.br>. Acesso em: 12 mar. 2016.

MESSIAS, N. C.; MIRANDA, E. L. . Escolas do Campo: um olhar para as práticas educativas, na região sudeste do Estado do Tocantins, Brasil.. Revista Márgenes, v. 13, p. 41-46, 2016.

MOLINA, Mônica Castagna. SÁ, Lais Mourão. Escola do Campo. In: CALDART, Roseli Salete; PEREIRA, Isabel Brasil, ALENTEJANO, Paulo; FRIGOTTO, Gaudêncio. Dicionário da Educação do Campo. Rio de Janeiro, São Paulo: Escola Politécnica de Saúde Joaquim Venâncio, Expressão Popular, 2012. p. 336-332.

MST. MOVIMENTO DOS TRABALHADORES RURAIS SEM TERRA. Mais de 4 mil escolas do campo fecham suas portas em 2014. 2015. Disponível em: $<$ http://www.mst.org.br/2015/06/24/mais-de-4-mil-escolas-do-campo-fechamsuas-portas-em-2014.html>. Acesso em: 18 de jan. 2016.

MUNARIM, Antônio. Movimento Nacional de Educação Do Campo: Uma trajetória em Construção. UFSC. GT-03: Movimentos Sociais e Educação. Caxambu - MG, 2008. Disponível em: <31 reuniao.anped.org.br/1trabalho/GT034244--Int.pdf>. Acesso em: 18 de janeiro de 2016.

SEMED. Secretaria Municipal de Educação. Combinado-TO, 2015.

TAFFAREL, Celi Nelza Zülke; JÚNIOR, Claúdio de Lira Santos; ESCOBAR, Micheli Ortega (org.). Cadernos Didáticos sobre Educação do Campo. Salvador, 2010

TAFFAREL, Celi Nelza Zülke; MUNARIM, Antonio. Pátria Educadora e Fechamento de Escolas do Campo: O Crime Continua. Revista Pedagógica, Chapecó, v. 17, n. 35, p. 41-51, maio/ago. 2015.

TRIVIÑOS, Augusto Nibaldo Silva. Introdução à pesquisa em ciências sociais: a pesquisa qualitativa em educação. 1. Ed. 19. Reimpr. São Paulo: Atlas, 2010. 


\section{Sobre os autores}

\section{Edivaldo Barbosa de Almeida Filho}

aedivaldo70@gmail.com

Graduando em Licenciatura em Educação do Campo habilitações em Artes Visuais e Música na Universidade Federal do Tocantins - UFT. Membro do Laboratório Multidisciplinar de Formação e práticas educacionais dialógicasLampedi. Atuando na Formação Multidisciplinar e Intervenção Pedagógicas na Educação Básica Formação docente, Novas tecnologias da informação e comunicação na Educação, Grupo de Estudos e Pesquisas \&quot;História, Sociedade e Educação no Brasil\&quot; no DF, HISTEDBR - DF - HISTEDBR, orientado pela professora Eliana Gonçalves da Silva Fonseca.

\section{Deyvison Bispo de Oliveira Santos}

dbosantos@uft.edu.br

Formado em pedagogia pela Universidade Federal do Tocantins-UFT. Pósgraduando em Gestão, Supervisão e Orientação escolar. Atualmente é professor efetivo da rede de educação básica do município de Porto Nacional/TO. Lotado na Escola Municipal Professora Fany de Oliveira Macedo, vinculado à Secretaria municipal de educação.

\section{Sátila Menezes Aires}

satila.sma@gmail.com

Formada em Pedagogia e Administração Pública pela Universidade Federal do Tocantins - UFT, Pós-Graduada em Psicopedagogia, Educação do Campo e Práticas Pedagógicas e Educação Pobreza e Desigualdade Social. Atua como Educadora Social na Secretaria Municipal de Assistência Social de CombinadoTO.

\section{Floriza Beatriz de Sena Paula}

florizabeatriz@gmail.com

Graduanda em Licenciatura em História pela Universidade Federal de Ouro Preto. Bolsista do Programa Institucional de Bolsas de Iniciação Científica (PIBIC/CNPq), do projeto \&quot;Consumindo o historicismo através dos Almanaques Anuais (1830-1870): Historiografias populares e distância histórica sob a orientação do professor Dr. Valdei Lopes de Araujo. Membro do Núcleo de estudos Afro-brasileiros e Indígenas (NEABI) e do Núcleo de Estudos em História da Historiografia e Modernidade (NEHM). Também, membro do Coletivo Negro Braima Mané (CNBM) e do Centro Acadêmico de História | Olga Benário (CAHIS). Orcid: https://orcid.org/0000-0001-8809-191X 